RGSA - Revista de Gestão Social e Ambiental

Set.- Dez. 2009, V.3, No.3, p.137-154

www.gestaosocioambiental.net

\title{
POLÍTICA AMBIENTAL: UMA ABORDAGEM ANALÍTICA DO DESENHO POLÍTICO-INSTITUCIONAL PARA A SUA INSTRUMENTALIZAÇÃO NA GESTÃO AMBIENTAL EMPRESARIAL NO BRASIL
}

\author{
Maria Gracinda Carvalho Teixeira ${ }^{1}$
}

Luis Peres Azevedo ${ }^{2}$

\section{RESUMO}

Este trabalho trata da Política Ambiental sob uma abordagem analítica a qual permite identificar a dinâmica da sua arquitetura político-institucional. Privilegiaram-se os instrumentos que se intitulam Estudos de Impacto Ambiental e Licenciamento Ambiental, sem os quais, como determina a legislação ambiental brasileira, os empreendimentos de potencial poluidor não se viabilizam. A abordagem permite uma interface teórico-conceitual e metodológica e considera que o desenho político-institucional existente e não somente os aspectos técnicos determinam as condições para a incorporação (ou não) dos instrumentos na gestão ambiental empresarial no país. A pesquisa é qualitativa, abrangendo revisão da literatura e análise documental, tendo como base empírica do estudo a empresa brasileira Eletrobrás Termonuclear S. A. (Eletronuclear), cuja atividade produtiva é geradora de fortes polêmicas de cunho político e sócio-ambiental. Envolveram-se também sujeitos que atuam na formulação, regulação, implementação, fiscalização e controle de Política Ambiental no país. Os resultados do estudo revelam de um lado, avanços na utilização dos instrumentos por força de pressão da sociedade e de mecanismos legais e de outro, dinâmicas conflituosas que influenciam a utilização compartilhada e o controle social dos instrumentos analisados.

Palavras-chave: Política Ambiental; Abordagem Analítica; Gestão Ambiental Empresarial; Instrumentalização.

\section{ABSTRACT}

This work concerns Environmental Policy, by approaching it with an analysis which allows identification of its political and institutional structure and dynamics. The instruments entitled Studies of Environmental Impact and Environmental Licensing were highlighted, without which, as determined by Brazilian environmental legislation, potential polluting businesses will not be made viable. The approach permits a theoretical-conceptual and methodological interface and considers that the existing political-institutional design, besides the technical aspects, determines the criteria which will allow or prevent incorporation from the instruments in environmental and business administration in the country. The research is qualitative, covering document literature and analysis, having as an empirical base for study, the Brazilian company Eletrobras Termonuclear S. A. (Electronuclear), whose productive activity generates strong controversies of a political and socio-environmental flavor. There

\footnotetext{
${ }^{1}$ Doutora em Ciências Ambientais pela University of East Anglia, UK, professora e pesquisadora em Gestão Ambiental nas Organizações e Desenvolvimento Local e Regional no PPGA/UNIGRANRIO. gracinda@uol.com.br

${ }^{2}$ Mestre em Administração pelo PPGA/UNIGRANRIO. Gestor de projetos do PEX/Governo Federal no INSS. O presente artigo é um produto da sua dissertação, sob orientação do primeiro autor.

luispazevedo@yahoo.com.br
} 
were also other subjects involved, which act in the formulation, regulation, implementation, enforcement and control of the country's environmental policy. The results of the study reveal, on one hand, advances in the use of the instruments due to pressure from society and legal means, and on the other hand, conflicting dynamics which influence the shared use and social control of the analyzed instruments.

Key words: Environmental Policy; Analytical Approach; Environmental-Business Administration; Technical Instruments.

\section{INTRODUÇÃO}

Este trabalho analisa a Política Ambiental sob uma ótica analítica que permite estabelecer uma interface teórico-conceitual e metodológica por meio do diálogo entre diferentes correntes e ao mesmo tempo complementares. Assim sendo, construiu-se um aporte teórico-metodológico desejável à realização da pesquisa. A pesquisa dedica-se aos instrumentos de política pública ambiental intitulados Estudos de Impacto Ambiental (EIAs) acompanhados de Relatórios de Impacto Ambiental (RIMA's) e o Licenciamento Ambiental sem os quais os empreendimentos industriais de potencial poluidor não se viabilizam de acordo com o que determina a legislação brasileira. Verificam-se quais são as dificuldades político-institucionais e não somente técnicas hoje postas à utilização desses instrumentos abordando criticamente a articulação interinstitucional que influencia as condições para a incorporação dos mesmos na gestão empresarial no Brasil, a partir da experiência de uma empresa brasileira de grande porte, a Eletrobrás Termonuclear S. A. (Eletronuclear).

A elaboração de um EIA é apoiada em estudos ambientais os quais apresentam diagnósticos, descrições, análises e avaliações sobre os impactos ambientais no sentido amplo do termo, efetivos e potenciais do projeto, incluindo aspectos sociais, econômicos, urbanísticos, entre outros. Já o Relatório de Impacto Ambiental, documento que reflete todas as conclusões apresentadas num EIA deve ser elaborado de forma objetiva e em linguagem acessível inclusive ilustrado por mapas, quadros, gráficos entre outros recursos para facilitar o seu entendimento no processo de participação pública. O Licenciamento Ambiental é o procedimento administrativo pelo qual o órgão ambiental competente licencia a localização, instalação, ampliação e operação de empreendimentos e atividades utilizadoras de recursos ambientais, consideradas efetivas ou potencialmente poluidoras, ou daquelas que, sob qualquer forma, possam causar degradação ambiental, considerando as disposições legais e regulamentares e as normas técnicas aplicadas ao caso.

No tocante à formulação da Política Ambiental, no Brasil emergiram e consolidaramse importantes movimentos e mudanças no campo da proteção ao meio ambiente, ressaltandose principalmente: a obrigatoriedade de estudos de impacto ambiental em empreendimentos potencialmente poluidores; o fortalecimento do quadro legal e do aparelho institucional de proteção do meio ambiente; maior eficácia e presença do Ministério Público, do Poder Judiciário, dos órgãos públicos e das organizações civis no licenciamento e na fiscalização de empreendimentos que permitem o controle social e embargos freqüentes de estudos, instalações e operação de empreendimentos por ação judicial ou mobilização de segmentos da sociedade. Esse conjunto de mudanças tem impacto direto e, por vezes, decisivo nas atividades de expansão, produção e distribuição de energia elétrica e em toda a indústria do petróleo, exigindo-se dos atores intervenientes um gerenciamento pró-ativo e especializado das questões ambientais pertinentes ao seu campo de atuação (Porto e Belfort, 2006).

Assim torna-se necessário entender o quadro de conflitos interinstitucionais em torno das mudanças dos rumos da Política Ambiental uma vez configurada a importância do 
estabelecimento de novos patamares de relacionamento entre o setor empresarial energético e o segmento ambiental com a adoção de ferramentas, prioridades e de novos arranjos de natureza política e técnico-institucional para o encaminhamento de soluções compartilhadas. Nesse contexto, registram-se por um lado avanços na formulação da Política Ambiental brasileira na sua instrumentalização e por outro, impasses nos mecanismos de controle social por meios comunicacionais entre instituições, empresa e sociedade no que tange aos impactos ambientais da atividade produtiva.

O trabalho está organizado em oito seções. Na primeira que trata da introdução, dá-se uma discussão contextualizada em torno das dificuldades e impasses historicamente presentes na utilização dos instrumentos de Política Ambiental no que dizem respeito às questões técnicas e político-institucionais. Na segunda seção discorre-se sobre a abordagem teóricometodológica adotada no estudo. Na terceira seção, discute-se sobre adequação das empresas às políticas ambientais. Na quarta, apresenta-se o aporte crítico sobre as mudanças institucionais e políticas públicas. Segue-se com a apresentação dos instrumentos de política ambiental. Na sexta seção apresenta-se a análise do desenho político-institucional da instrumentalização da política ambiental, com ênfase no mapeamento da percepção dos sujeitos. Na sétima seção apresentam-se as conclusões do estudo. Finalmente na última seção relacionam-se as referências bibliográficas do estudo.

\section{ABORDAGEM TEÓRICO-METODOLÓGICA}

O trabalho permite avançar nos estudos sobre a relação entre Política Ambiental e a gestão ambiental nas empresas apresentando uma abordagem que rompe com as fronteiras rígidas do conhecimento à medida que apresenta uma interface teórico-conceitual e metodológica que coloca a contribuição de diferentes vertentes do institucionalismo. A que surge no âmbito das ciências sociais resgatando idéias pioneiras do institucionalismo no âmbito da economia, de Thorstein Veblen (1919 apud Hogson, 1988) e de Selznick (1996) e uma vertente do neo-institucionalismo defendido por Scott (1983) e por Crubelatte (2007).

Diferentemente dessas vertentes, mas complementando-as, ao expor as fragilidades tanto do institucionalismo quanto do neo-institucionalismo outros autores auxiliam na construção da interface teórico-conceitual e metodológica tornando possível o viés analítico proposto, o que será visto em tópicos subseqüentes. O material a que se teve acesso na literatura pertinente revela dois ângulos distintos das pesquisas sobre o tema em questão: ou se tem estudado sobre a eficácia dos instrumentos na sua dimensão técnica sem considerar os aspectos político-institucionais ou se tem debruçado sobre a Política Ambiental sem relacioná-la à sua dinâmica técnico-operacional. Ao lado disso, não se tem considerado, na literatura brasileira, que condições existem nas empresas para internalizarem mudanças institucionais que dizem respeito à sua Política Ambiental. Também não se teve acesso a pesquisas que apontam que inovações no âmbito empresarial podem estimular mudanças institucionais.

A escolha da empresa Eletronuclear como base empírica do estudo deve-se a vários fatores. O debate sobre os projetos energéticos por ela realizados - suas usinas nucleares, Angra 1 e Angra 2 - percorre diversas décadas do desenvolvimento social e econômico brasileiro. A construção das respectivas usinas se deu em década de 1970, época de conturbada conjuntura político-social brasileira - durante o regime ditatorial militar, em que as decisões sobre as políticas desenvolvimentistas se davam sem a participação da sociedade civil, inclusive da comunidade científica nacional e muitas vezes as políticas eram decididas e monitoradas no âmbito internacional. Essa época antecedeu a criação da Política Nacional de Meio Ambiente no Brasil, em 1981 e a expansão dos projetos de produção de energia nuclear no país. A construção de futuras plantas nucleares, por exemplo, a Angra 3 está em curso no 
desenvolvimento da política industrial e de infraestrutura do país. Assim, a escolha da empresa e a sua atuação ao longo de décadas permitiu identificar as mudanças ocorridas na utilização dos instrumentos, levando-se em consideração o contexto político-institucional em que estas ocorreram envolvendo arrojados debates sobre segurança e risco no contexto das questões ambientais no Brasil e no mundo.

A pesquisa é qualitativa sendo descritiva e a analítica, o que foi levado a efeito através de fontes bibliográficas, documentais e a pesquisa empírica. Na pesquisa empírica, que denominamos nesse estudo como "de campo", adotou-se entrevistas gravadas e de longa duração, com roteiros semi-estruturados por possuir características comunicativas apropriadas para esse tipo de pesquisa, pois a ação comunicativa favorece um processo interativo entre entrevistador e entrevistado e auxilia no envolvimento e convencimento por meio de argumentos, poder e conhecimento (Habermas, 1984). Para Habermas, a ação comunicativa tem um caráter dual - deve conduzir a entrevista para o alcance do entendimento comum às partes envolvidas - a que questiona e a que responde, entretanto nem sempre com o objetivo de favorecer o propósito final nessa interação que se traduz no engajamento dos atores numa ação comunicativa. Por exemplo, entrevistas conduzidas com pessoas que atuam em níveis hierárquicos mais elevados nas organizações, como é o caso do presente estudo, podem gerar discursos estratégicos e de construção de imagem, dissimulando ou camuflando conflitos que perpassam a comunicação entre as partes envolvidas. Mishler (1986, p. 64) compartilha da visão de Habermas e acrescenta que "a entrevista é um tipo de discurso" com o potencial de empoderamento do entrevistado no sentido de encorajar e atribuir conhecimento ao respondente e assim tornar possível a ação comunicativa. Argumenta Mishler (1986, p. 65):

[...] entrevistadores e respondentes, através de formulações e reformulações de questões e respostas conseguem chegar juntos a significados que ambos podem entender. A relevância e a apropriação das respostas emergem através do discurso e são realizadas no discurso.

Esses são aspectos importantes que não se pode descuidar na coleta e análise dos dados empíricos quando se opta por abordagens mais subjetivas na pesquisa qualitativa.

Os sujeitos da pesquisa foram instituições e empresa que atuam no contexto da Política Ambiental brasileira, de acordo com o que determina a legislação ambiental do país. Segundo o Conselho Nacional de Meio Ambiente (CONAMA), estas devem ser as partes envolvidas nos processo de Avaliação de Impactos Ambientais e Licenciamento Ambiental de maneira geral. Assim, relacionam-se como principais sujeitos: representantes da Eletrobrás Termonuclear S. A. (Eletronuclear); representante Instituto Brasileiro do Meio Ambiente e dos Recursos Naturais Renováveis (IBAMA); representante da Fundação Estadual de Engenharia do Meio Ambiente (FEEMA); representante da Comissão Nacional de Energia Nuclear (CNEN); representante do poder público local, Secretaria de Meio Ambiente da Prefeitura do Município de Angra dos Reis; representantes da Comunidade Científica, particularmente os especialistas em Instrumentos de Política Ambiental e aqueles que estão diretamente envolvidos com os Relatórios Periciais relativos aos projetos de energia nuclear no país; representante de Organização Não Governamental (ONG) local; representante da Secretaria Executiva do Ministério do Meio Ambiente; representante do Ministério Público.

Para a análise dos dados utilizou-se a interpretação, procurando-se entender os seus significados tendo em vista a natureza qualitativa da pesquisa (GODOY, 1995; ROESCH, 2007). A limitação do método se revela principalmente no processo de análise e interpretação dos dados empíricos resultantes do discurso dos sujeitos privilegiados na pesquisa. A interpretação só pode ser realizada com base no conhecimento que foi transmitido pelos sujeitos no processo de coleta de dados. Assim considera-se o discurso do sujeito como o 
discurso da instituição que este representa. Tal entendimento coloca o pesquisador e a pesquisa num plano flexível e reflexivo, uma vez que, na busca de dados por meio do conhecimento dos respondentes selecionados, deposita-se a confiabilidade dos dados fornecidos, pois é o conhecimento desses sujeitos que irá gerar a "realidade” que se busca em campo.

\section{ADEQUAÇÃO DAS EMPRESAS ÀS POLÍTICAS AMBIENTAIS}

As empresas, tanto as brasileiras quanto as de outros países tentam se adequar às exigências resultantes de um mundo dinâmico, onde ocorrem freqüentes mudanças e, simultaneamente, surgem novas oportunidades. Ao longo das últimas décadas com o aumento dos fluxos do comércio internacional aliado a acordos empresados no âmbito do Acordo Geral de Tarifas e Comércio - GATT, as barreiras tarifárias foram perdendo importância relativa para barreiras não tarifárias ambientais, que são conhecidas como "barreiras verdes" sob o argumento de que os países em desenvolvimento possuiriam leis ambientais menos rigorosas que os países desenvolvidos, o que resultaria em custos mais baixos - também chamados dumping ecológico - e conseqüentemente, em menores preços praticados no mercado internacional (Lustosa, 2003). Explica a autora que, além da pressão dos mercados externos, o Estado, por meio da gestão ambiental pública, teve que fazer uso de meios legais - a Política Ambiental de suas regulamentações - e incentivar suas empresas a mudarem o seu comportamento em relação aos impactos ambientais resultantes da suas atividades.

Para as empresas dos segmentos de petróleo e gás e de energia, há uma tendência a um alinhamento e integração da norma ISO 14001, Sistema de Gestão de Meio Ambiente com a norma de Sistema de Gestão de Segurança e Saúde, a OSHAS 18001 o que se configura como uma exigência hoje da Política Ambiental das empresas (Oliveira; Borges; Melhado, 2007). Explicam Lustosa, Cánepa e Young (2003) que a Política Ambiental é necessária para induzir ou forçar os agentes econômicos a adotarem posturas e procedimentos menos agressivos ao meio ambiente, para reduzir a quantidade de poluentes lançados no ambiente e minimizar o consumo de recursos naturais. Os instrumentos de Política Ambiental então começaram a ser elaborados e implementados, segundo a tipologia abaixo relacionada por Lustosa, Cánepa e Young (2003, p. 142) e Barbieri (2007, p. 73). Os instrumentos de comando e controle são aqueles mais utilizados pelos agentes públicos, segundo a legislação e é nessa classificação que se encontram os instrumentos privilegiados na pesquisa, o Estudo de Impacto Ambiental e o Licenciamento Ambiental. Segundo Lustosa, Cánepa e Young (2003, p. 136), os instrumentos de comando e controle assumiram duas características muito definidas:

(i) A imposição pela autoridade ambiental de padrões de emissão incidentes sobre a produção final (ou sobre o nível de utilização de um insumo básico) do agente poluidor;

(ii) A determinação da melhor tecnologia disponível para abatimento da poluição e cumprimento do padrão de emissão

Os instrumentos de comando e controle, em particular os que interessam diretamente à presente pesquisa, quais sejam, os Estudos de Impactos Ambiental e o Licenciamento Ambiental, os quais ocuparam um lugar privilegiado nas pesquisas científicas no Brasil e no mundo em décadas passadas, voltam a ser objeto de estudo uma vez que, as exigências ambientais por força das legislações dos países ou por pressão da sociedade têm se ampliado, estimulando novos estudos sobre os grandes projetos de investimento nos quais as questões ambientais têm ocupado um lugar central nas arenas de conflitos e lutas de interesses que perpassam as decisões sobre a implementação desses projetos. 
Quadro 1 - Instrumentos de Política Ambiental

\begin{tabular}{|c|c|c|}
\hline $\begin{array}{l}\text { COMANDO E } \\
\text { CONTROLE }\end{array}$ & ECONÔMICOS & COMUNICAÇÃO \\
\hline $\begin{array}{l}\text { Controle ou proibição de } \\
\text { produto }\end{array}$ & Tributação sobre poluição & Fornecimento de informação \\
\hline Controle de processo & $\begin{array}{l}\text { Tributação sobre uso de } \\
\text { recursos naturais }\end{array}$ & Acordos \\
\hline $\begin{array}{l}\text { Proibição ou restrição de } \\
\text { atividades }\end{array}$ & $\begin{array}{l}\text { Incentivos fiscais para reduzir } \\
\text { emissões e conservar recursos }\end{array}$ & Criação de redes \\
\hline Especificações tecnológicas & $\begin{array}{l}\text { Remuneração pela } \\
\text { conservação de serviços } \\
\text { ambientais }\end{array}$ & Sistema de gestão ambiental \\
\hline $\begin{array}{l}\text { Controle do uso de recursos } \\
\text { naturais }\end{array}$ & $\begin{array}{l}\text { Financiamentos em condições } \\
\text { especiais }\end{array}$ & Selos ambientais \\
\hline $\begin{array}{l}\text { Padrões de poluição para } \\
\text { fontes específicas }\end{array}$ & $\begin{array}{l}\text { Criação e sustentação de } \\
\text { mercados de produtos } \\
\text { ambientalmente saudáveis }\end{array}$ & Marketing ambiental \\
\hline Padrão de emissão & Permissões negociáveis & $\begin{array}{l}\text { Apoio ao desenvolvimento } \\
\text { científico e tecnológico }\end{array}$ \\
\hline Padrão de qualidade & Sistemas de depósito-retorno & Educação ambiental \\
\hline Padrão de desempenho & & Unidades de conservação \\
\hline Padrões tecnológicos & 1/2. & \\
\hline $\begin{array}{l}\text { Proibições e restrições sobre } \\
\text { produção, comercialização e } \\
\text { uso de produtos e processos }\end{array}$ & & \\
\hline Estudo de impacto ambienta & & \\
\hline Licenciamento ambiental & & \\
\hline Zoneamento ambiental & & \\
\hline
\end{tabular}

Fontes: Elaboração própria com base em Lustosa; Cánepa; Young (2003, p. 142) e Barbieri (2007, p. 73).

\section{MUDANÇAS INSTITUCIONAIS E POLÍTICAS PÚBLICAS: UMA ABORDAGEM ANALÍTICA}

Tendo em vista as dimensões técnica e político-institucional inerentes aos instrumentos de Política Ambiental em análise - os Estudos de Impacto Ambiental e o Licenciamento Ambiental, pretende-se nesse tópico esboçar de forma crítica a contribuição do enfoque institucional dos estudos organizacionais, o que surge no âmbito das ciências sociais resgatando idéias pioneiras do institucionalismo no âmbito da economia, de Thorstein Veblen (1919 apud Hogson, 1988) e o neoinstitucionalismo que evoluiu no campo da Administração representado por suas diferentes vertentes defendidas distintamente por Selznick (1996), Scott (1983) e por Crubelatte (2007) que apresentam conseqüentemente contribuições diferenciadas e complementares. O estudo das instituições oferece uma forma de examinar as bases de ações que se tornam rotinas padronizadas do ponto de vista do sistema como um todo (Veblen, 1919 apud Hodgson, 1988).

Segundo Scott (1983) a perspectiva neoinstitucional abandona a concepção de um ambiente formado exclusivamente por recursos humanos, materiais e econômicos para destacar a presença de elementos culturais - valores, símbolos, mitos, sistema de crenças e programas profissionais. O neoinstitucionalismo imprimiu novos elementos como os sociais, 
culturais e cognitivos que se apresentam tão poderosos quanto os aspectos econômicos dos ambientes organizacionais. Entretanto de acordo com Peci (2006) uma das limitações do novo institucionalismo, apesar de ampliado o seu entendimento das instituições e da sociedade, representado por Scott (1983), é que permanece tratando o ambiente técnico como distinto do ambiente institucional, ao distinguir as regras institucionalizadas dos comportamentos sociais predominantes (Peci, 2006). Concordando com Peci, a pesquisa que se apresenta aponta para o fato de que as regras institucionalizadas são classificações construídas pela sociedade ou interpretações compartilhadas como nos chamam atenção Berger e Luckman (2001 apud Peci, 2006).

Com base na compreensão das limitações do novo institucionalismo apesar do reconhecimento da sua relevante contribuição para estudo em foco, outros aportes teóricos foram utilizados, conforme exposto na metodologia do trabalho. Para entender como a sociedade cria relações sobre a aparente dicotomia posta pelo neoinstitucionalismo entre ambiente técnico e ambiente institucional, sugere-se uma interface teórica com a contribuição de Nunes (1997) e Oliveira (2003) que falam da interferência política sobre a tecnocracia e o insulamento burocrático próprios de algumas instituições públicas o que pode afetar a consecução dos objetivos, seja em função da lentidão da burocracia e do processo de negociação ou da preservação do conteúdo racional da política pública. Nunes, em trabalho mais recente sobre as agências reguladoras no contexto da pós-privatização no Brasil, reforça as suas idéias anteriores confirmando que a dinâmica insulativa que recai sobre o modelo regulatório brasileiro não é neutra, nem inocente; influencia relações conflituosas tornando o mercado regulatório um "selvagem campo de lutas de interesses” (Nunes, 2001, p. 2).

No Brasil, houve a busca por organizações de elevada capacidade operativa exigida pela infraestrututra industrial do país, mas que convivesse com o aparato tradicional de Estado. Através desta busca o Estado conseguiu implementar projetos desenvolvimentistas em diferentes momentos históricos, às vezes sendo percebido como autoritário seja ao alocar recursos, seja fazendo impor suas decisões políticas. O tema envereda, portanto, pela questão da força e da autonomia do Estado, em que muitas vezes deu-se preferência à tecnocracia em detrimentos das ações políticas objetivas, calcadas no modelo mais tradicional de Estado. Houve, ao longo do tempo, uma adequação das instituições brasileiras, que procuraram unir capacitações técnicas às condicionantes políticas, visando ao estabelecimento de uma Política Ambiental Pública coerente.

A interface teórica reforça-se com as idéias de Crubellate (2007), segundo as quais não se pode analisar um padrão ambiental institucional sem analisar as ações que o constituem, sustentam ou alteram, como se fosse um estado final, congelados, independentes. Para o autor também, não há sentido em analisar ações de modo isolado, como se não demandassem o estímulo ou perturbação e a estabilização, proporcionados por padrões nos ambientes institucionais. $\mathrm{O}$ autor propõe que o processo institucional seja um processo de contínua transformação, formação e desconstrução, que possua sempre um lado concreto e exterior e que dependa das relações travadas no cotidiano entre os atores por este afetados. Crubellate ressalta, portanto, que "a correlação entre estruturas e ações organizacionais é circular” (2007, p. 217). Argumenta que, do mesmo modo que estruturas influenciam ações institucionais, também as forças do ambiente organizacional entram em processo de institucionalização. Dessa forma pressupõe-se que assim como as organizações incorporam mudanças institucionais, estas podem proporcionar um ambiente inovador que motivaria mudanças institucionais. 
Os Estudos de Impacto Ambiental e o Licenciamento Ambiental foram instituídos pela Política Nacional de Meio Ambiente (PNMA), sob a Lei $n^{0} 6.938$ de 1981 (IBAMA, 2008) que inovou no plano institucional ao criar o Sistema Nacional do Meio Ambiente SISNAMA (Souza; Jacobi, 2007), uma estrutura articulada de órgãos governamentais nas três esferas: nacional, estadual e municipal.

No conjunto das inovações institucionais, nessa época, foi criado também por recomendação do Banco Mundial, o Conselho Nacional de Meio Ambiente (CONAMA), composto por representantes da sociedade civil, como empresários, sindicatos e organizações não governamentais (Teixeira; Bessa, 1990; Teixeira; Souza; Magrini; Rosa, 1994; Souza; Jacobi, 2007). Coube ao CONAMA o papel de regulamentar a Lei $n^{0}$ 6.938/81 e de formular diretrizes da Política Ambiental. Cabe ressaltar que os processos de EIA/RIMA e de Licenciamento Ambiental só se tornaram efetivos a partir da Resolução n ${ }^{0} 001$ CONAMA, cinco anos mais tarde, em 1986, que estabeleceu uma lista de atividades sujeitas aos EIA/RIMA entre elas diversas atividades industriais consideradas modificadoras do meio ambiente.

Nessa época em que se discutiam os chamados projetos de grande investimento industrial no contexto do desenvolvimento brasileiro, o CONAMA veio determinar as condições para que as atividades de potencial poluidor pudessem passar pelo processo de licenciamento (Teixeira; Bessa, 1990; Teixeira; Souza; Magrini; Rosa, 1994 ).

Os órgãos responsáveis pelo licenciamento no âmbito dos estados são os órgãos estaduais de meio ambiente e no âmbito federal, o IBAMA, através da Diretoria de Licenciamento Ambiental, atuante, sobretudo em projetos de infraestrutura que atinjam mais de um estado, bem como nas atividades de energia, petróleo e gás e na plataforma continental. Tanto os EIA's quanto os RIMA's devem ser elaborados por profissionais legalmente habilitados a expensas do empreendedor (BRASIL/CONAMA, 1997). No entanto, Barbieri (2007) explica que até o advento da Resolução n⿳0 237 de 1997 do Conselho Nacional do Meio Ambiente, o EIA/RIMA, por lei, deveria ser elaborado por equipes multidisciplinares independentes do proponente do projeto.

A fiscalização da habilitação passou a ser de responsabilidade de instâncias dos Conselhos Regionais Profissionais. A Lei $\mathrm{n}^{0}$ 6.938/81, que definiu a Política Nacional de Meio Ambiente (PNMA), lança as bases dos instrumentos de Licenciamento Ambiental e define sua obrigatoriedade e discorre sobre as etapas de um licenciamento. No mesmo sentido a Resolução CONAMA n ${ }^{0}$ 237/97 expande a definição dessas etapas e inclui o grau de competência dos órgãos ambientais quanto ao licenciamento.

O EIA/RIMA não figura sozinho no rol dos instrumentos de licenciamento prévio. Há também o Plano de Controle Ambiental (PCA) e o Relatório de Controle Ambiental (RCA). O PCA/RCA se destina a planejar a avaliação do impacto de atividades capazes de gerar dano ao ambiente, através de planos de monitoração.

Registram-se na literatura internacional estudos pioneiros sobre o papel e a competência dos EIA/RIMA's. Ressaltam-se principalmente os trabalhos de Bolea (1984) e Westman (1985). No Brasil, registram-se os trabalhos de Magrini (1989), Teixeira e Bessa (1990), Teixeira, Souza, Magrini e Rosa (1994). Estes dois últimos mostram a complexidade do uso desses instrumentos e a sua pouca eficácia na conjuntura político-econômica estudada pelos autores.

A participação da sociedade no processo de licenciamento ocorre através das Audiências Públicas, durante as quais os conteúdos do estudo e do Relatório de Impacto Ambiental são apresentados às comunidades que vivem nos locais que serão atingidos pelo empreendimento, esclarecendo dúvidas e acolhendo sugestões. São realizadas por solicitação do IBAMA, ou de entidade civil, ou do Ministério Público ou por um grupo de no mínimo 50 (cinquenta) cidadãos. O edital de realização das audiências deve ser publicado no Diário 
Oficial e nos meios de comunicação locais, com indicação de data, hora e local do evento. O local deve ser de fácil acesso às comunidades (IBAMA, 2008).

$\mathrm{Na}$ atual conjuntura brasileira, em que novos investimentos industriais se iniciam, assim como polêmicos e antigos projetos dão continuidade, os instrumentos de Política Ambiental passam a ocupar um lugar estratégico no planejamento ambiental empresarial. O EIA deve ser entendido como uma etapa integrante do próprio projeto de obra ou de atividade potencialmente causadora de degradações significativas no meio ambiente. No Brasil, a aprovação do EIA pelo órgão governamental competente é condição necessária para a continuidade do processo de licenciamento do empreendimento ou atividade proposta. $\mathrm{O}$ Conselho Nacional de Meio Ambiente (CONAMA) instituiu a Resolução CONAMA n⿳ 237 de 1997, que definiu Licenciamento Ambiental e o relacionou aos EIA’s da seguinte maneira:

I - Licenciamento Ambiental: procedimento administrativo pelo qual o órgão ambiental competente licencia a localização, instalação, ampliação e operação de empreendimentos e atividades utilizadas de recursos ambientais, consideradas efetivas ou potencialmente poluidoras, ou daquelas que, sob qualquer forma, possam causar degradação ambiental, considerando as disposições legais e regulamentares e as normas técnicas aplicadas ao caso.

II - Estudos de Impacto Ambientais: são todos e quaisquer estudos relativos aos aspectos ambientais relacionados à localização, instalação, operação e ampliação de uma atividade ou empreendimento, apresentados como subsídios para a análise da licença requerida [...] (Brasil/CONAMA, 1997 art. $1^{\underline{0}}$ ).

A interligação entre os EIA’s e o Licenciamento Ambiental nas etapas consideradas para o licenciamento é determinada pela legislação:

I - Definição pelo órgão ambiental competente, com a participação do empreendedor, dos documentos, projetos e estudos ambientais, necessários ao início do processo de Licenciamento correspondente à licença a ser requerida;

II - Requerimento da licença ambiental pelo empreendedor, acompanhado dos documentos, projetos, estudos ambientais pertinentes, dando-se a devida publicidade;

III - Análise pelo órgão ambiental competente, integrante do SISNAMA, dos documentos, projetos e estudos ambientais apresentados e a realização de vistorias técnicas quando necessárias;

IV - Solicitação de esclarecimentos e complementações pelo órgão ambiental competente, integrante do SISNAMA, uma única vez, em decorrência da análise dos documentos, projetos e estudos ambientais apresentados, quando couber, podendo haver a reiteração da mesma solicitação caso os esclarecimentos e complementações não tenham sido satisfatórios;

V - Audiência pública, quando couber, de acordo com a regulamentação pertinente;

VI - Solicitação de esclarecimentos e complementações pelo órgão ambiental competente, decorrentes de audiências públicas, quando couber, podendo haver a reiteração da solicitação, caso os esclarecimentos e documentações não tenham sido satisfatórios;

VII - Emissão de parecer técnico conclusivo e, quando couber, parecer jurídico;

VIII - Deferimento ou indeferimento do pedido de Licença dando-se a devida publicidade (Brasil/CONAMA, Resolução $n^{0}$ 237, 1997, art.10ํㅜ). 
A interdependência entre os Estudos de Impactos Ambientais e o processo de licenciamento estabelecida em lei vem favorecer a incorporação destes instrumentos no Sistema de Gestão Ambiental (SGA) das empresas, uma vez que tem ocorrido uma valorização destes instrumentos que haviam caído em descrédito durante um longo período durante o qual se questionou sobre a sua real efetividade (Magrini, 1989; Teixeira; Bessa, 1990; Teixeira; Souza; Magrini; Rosa, 1994). Em contrapartida, recentes estudos sobre o Licenciamento Ambiental (Barbieri, 2007; Souza; Jacobi, 2007) apontam que a eficácia do instrumento poderá ser percebida no controle e boa gestão governamental, pois tanto o Licenciamento Ambiental como o EIA/RIMA são regidos por normas de poderes públicos - União, Estados e Municípios. Em que pese toda esta regulamentação federal, também existem os órgãos estaduais de Licenciamento. O órgão responsável no Rio de Janeiro é a Fundação Estadual do Meio Ambiente (FEEMA) que, a partir da Lei Estadual n⿳0 1.356 de outubro de 1988, passou a exigir os EIA/RIMA’s e o requerimento de Licença Prévia para instalação ou ampliação dos empreendimentos na esfera estadual.

\section{APRESENTAÇÃO E ANÁLISE DO DESENHO POLÍTICO-INSTITUCIONAL DA INSTRUMENTALIZAÇÃO DA POLÍTICA AMBIENTAL}

\section{1 A Empresa Eletronuclear}

Como descrito na metodologia deste trabalho, diversos fatores foram decisivos na escolha da empresa Eletronuclear. Uma empresa com as características específicas que possui permite compreender as condições para internalizar mudanças institucionais na sua Política Ambiental assim como a maneira como a empresa dialoga com os diversos segmentos da sociedade com esta finalidade.

Informações do Plano Nacional sobre Mudança no Clima (PNMC) - 2007, dos Estudos de Planejamentos Setoriais, e do Plano Nacional de Energia (PNE) - 2030 e o Plano Decenal de Energia (PDE) - 2016 indicam um crescimento da expansão termoelétrica de energia no Brasil. Isto decorre das justificativas técnicas constantes dos referidos planos segundo os quais é necessário incrementar a capacidade inexplorada do potencial hidrelétrico, opção brasileira primordial para geração de energia.

Alguns setores entendem que neste cenário a energia nuclear deveria assumir importante papel no plano de expansão de energia elétrica brasileiro, e os citados estudos de planejamento indicam um crescimento do parque nuclear brasileiro. Assim buscou-se compreender as razões que estimulam ou dificultam a empresa escolhida a adotar políticas ambientais e novos procedimentos para obter a Licenciamento Ambiental. Desta forma revelou-se a necessidade de entender as arenas de atuação e conflito entre a empresa e os outros sujeitos da pesquisa envolvidos não somente na formulação e execução das políticas, mas também no controle do uso dos instrumentos e sua efetivação na Gestão Ambiental Empresarial

Na Empresa foram realizadas três entrevistas em duas etapas. A primeira etapa com duas entrevistas (em 08 e 22 de abril de 2008) teve como objetivo focalizar os instrumentos de Política Ambiental em estudo. As respostas foram compartilhadas pelos dois técnicos entrevistados, o então Superintendente de Licenciamento e Meio Ambiente da Eletronuclear Sr. Iukio Ogawa e o Gerente de Meio Ambiente da Empresa, o Sr. Raimundo M. L. Ferreira. Numa segunda etapa, voltou-se à empresa para realizar entrevista com a Dr ${ }^{\mathrm{a}}$. Alessandra Kepinski da Superintendência de Licenciamento e Meio Ambiente (SM.G), com a finalidade de melhor compreensão da relação entre a empresa e os demais sujeitos. 


\subsection{O Instituto Brasileiro do Meio Ambiente e dos Recursos Naturais Renováveis (IBAMA)}

Órgão federal licenciador, vinculado ao Ministério do Meio Ambiente, o IBAMA é também o órgão responsável pela fiscalização de empreendimentos de grande envergadura, que cabem à esfera federal. Foi selecionado por ser um dos atores na articulação interinstitucional para a implementação dos instrumentos EIA/RIMA e Licenciamento Ambiental. Procedeu-se entrevista com a física nuclear, Dra . Sandra Cecília Miano, Diretora de Licenciamento Ambiental (DILIC), analista ambiental há nove anos, a qual recebeu o roteiro de perguntas por e-mail em 10 de janeiro de 2009.

\subsection{A Comissão Nacional de Energia Nuclear (CNEN)}

A CNEN foi escolhida porque é a agência reguladora da atividade nuclear no Brasil. Exerce também a função de órgão normatizador, licenciador e fiscalizador da atividade nuclear e por isto, foi entrevistado pessoalmente, em 20 de outubro de 2008, o Dr. Alexandre Gronman - gerente da Gerência de Reatores e Ciclo Combustíveis (GRCC).

\subsection{A Fundação Estadual de Engenharia do Meio Ambiente (FEEMA)}

A FEEMA, atualmente Instituto Estadual do Ambiente (INEA) foi escolhida por ser órgão Estadual Ambiental de fiscalização e por atuar no processo de Licenciamento Ambiental e de empreendimentos no âmbito estadual. Os empreendimentos da Eletronuclear apesar de serem federais, estão localizados no Estado do Rio de Janeiro. Portanto, foi entrevistada, em 07 de outubro de 2008, a Enga . Cláudia Semis - Diretora de Atividades não Industriais deste órgão.

\subsection{Poder Público Local (Secretaria Municipal do Meio Ambiente do Município de Angra dos Reis)}

A razão da escolha desta Secretaria deve-se ao fato de estarem localizadas neste município as atividades da Empresa Eletronuclear. A escolha justifica-se também em função do envolvimento do poder público nas questões que dizem respeito aos impactos dos empreendimentos sobre a infraestrutura urbana, questões relativas à regulação do uso do solo, entre outros aspectos relacionados aos problemas socioambientais e econômicos afetos ao empreendimento. Escolheu-se o Sub-Secretário Municipal do Meio Ambiente e de Desenvolvimento Urbano do Município de Angra dos Reis, o Engenheiro Florestal Ricardo Toledo, o qual concedeu uma entrevista no dia 22 de outubro de 2008.

\subsection{A Comunidade Científica}

A comunidade científica é importante ator na questão dos instrumentos de Política Ambiental e Licenciamento, pois, além de contribuir com os estudos sobre os instrumentos analisados na pesquisa, é chamada a participar, quando solicitada, pela Justiça, através do Ministério Público, para emitir pareceres técnicos por solicitação em alguma ação civil pública, particularmente aqueles profissionais que estão diretamente envolvidos com os Relatórios Periciais relativos aos projetos de energia no país. Não raro, cientistas são chamados a ocupar posições executivas dentro dos órgãos reguladores como o IBAMA, o Ministério do Meio Ambiente, entre outros órgãos, quando se especializam na academia. 
Foram, portanto, incorporados na pesquisa dois cientistas: um especialista envolvido com os relatórios periciais relativos aos Estudos de Impacto Ambiental relacionados à atividade nuclear e que tem desenvolvido projetos vinculados com o Licenciamento Ambiental das Usinas de Angra (atualmente coordenador do Projeto de Georreferenciamento do entorno do CNAAA - Central Nuclear Almirante Álvaro Alberto). Este último projeto foi exigido no Termo de Ajustamento de Conduta assinado em 2001 entre a CNEN e o Ministério Público Federal. Dr. Moacyr Duarte de Souza Júnior é professor e pesquisador sênior da COPPE, Universidade Federal do Rio de Janeiro. A entrevista foi realizada em 12 de novembro de 2008, no Rio de Janeiro. O outro especialista, mais envolvido com pesquisa sobre Política Ambiental Empresarial, escolhido para a entrevista, foi o Dr. José Carlos Barbieri, professor da Escola de Administração de Empresas de São Paulo da Fundação Getulio Vargas (EAESP/FGV). A entrevista foi realizada em 12 de agosto de 2008.

\subsection{Organização Não Governamental Local (ONG SAPE)}

A organização não governamental Sociedade Angrense de Proteção Ecológica (SAPE) tem se destacado como uma organização atuante junto às questões ambientais do país e mais especificamente às relativas à produção de energia de fonte nuclear. Tem participado das diversas audiências públicas, acompanhando passo a passo os procedimentos e levantando polêmicas junto ao Ministério Público, quanto aos quesitos referentes à operação das centrais nucleares. Promoveu em agosto de 2009 em parceria com a WWF, evento público neste município chamado "Hiroshima nunca mais”, com a participação das entidades locais, cujo tema principal foi a situação atual das plantas nucleares no município. Nesta ONG entrevistou-se o Sr. José Rafael Ribeiro, Diretor da ONG SAPE, em 22 de outubro de 2008 na sede da organização no Município de Angra dos Reis.

\subsection{Mapeamento da Percepção dos Sujeitos}

No presente tópico é apresentado um mapeamento sobre a percepção dos entrevistados com base na interpretação dos depoimentos prestados nas oito questões a estes dirigidas. $\mathrm{O}$ mapeamento permite expor as semelhanças e as divergências nas visões sobre as quais se a analisa a seguir. A complementação dos dados, para um melhor entendimento das diferentes visões apresentados na análise, foi também extraída dos depoimentos dos sujeitos.

Na primeira questão do quadro, sobre o que mudou na utilização dos EIA/RIMA's e Licenciamento Ambiental durante as duas últimas décadas, o órgão licenciador e fiscalizador ambiental brasileiro, o IBAMA, acredita que aumentou a transparência dos órgãos e a participação da população. Já o representante da Prefeitura do Município de Angra dos Reis acredita que houve um aumento de atribuições e responsabilidades, sem que o poder público tenha condições de acompanhar os procedimentos de execução do previsto nos EIA/RIMA's e nos relatórios gerados posteriormente, por falta de pessoal técnico capacitado para decifrar as informações contidas nos mesmos. A FEEMA atesta que os instrumentos têm sido cada vez mais aperfeiçoados, particularmente por ter sido o primeiro órgão ambiental criado no estado, em 1975; acredita-se que houve condições deste órgão acompanhar e participar das mudanças uma vez que atuou desde então, passando a implementar toda a legislação de sua competência de âmbito estadual que existe até hoje. A maioria dos entrevistados admite avanços no processo de Licenciamento Ambiental, que ao longo do tempo tornou-se mais detalhado e exigente, por pressão da sociedade civil, como confirmou a agência reguladora, CNEN. Entretanto a ONG SAPE afirma que os instrumentos EIA/RIMA's não evoluíram em nada e que a sociedade não tem acesso a dados ambientais preciosos. Acrescentou a ONG em 
entrevista que a fiscalização por parte dos órgãos competentes é falha no cumprimento das exigências posteriores ao Licenciamento Ambiental. Entretanto, a comunidade científica percebe o problema por outro ângulo, registrando que houve mudanças com a participação da sociedade civil pelo exercício da democracia. No entanto, ressalta que quanto aos empreendimentos que antecederam a Política Ambiental brasileira, as ações para minimizar ou eliminar os impactos indesejáveis passaram a consumir muitos recursos em função das poucas opções disponíveis, quando o ideal teria sido trabalhar as questões ambientais na fase de projeto do empreendimento.

Na segunda questão do quadro, sobre o que mudou quanto aos relatórios de Controle Ambiental definidos nos EIA's, os entrevistados ONG SAPE, a FEEMA e a Prefeitura do Município de Angra dos Reis queixam-se da complexidade técnica dos dados contidos nos relatórios, uma vez que não há nessas instituições pessoal técnico qualificado para analisá-los. Já a Empresa Eletronuclear crê que tem apresentado relatórios cada vez mais aperfeiçoados e que refletem com fidelidade a situação ambiental. Por parte da Prefeitura registra-se que o órgão não possui condições de acompanhar os relatórios o que está coerente com o depoimento sobre a questão anterior, que também registra a falta de pessoal capacitado. A CNEN atesta que estes têm sido aperfeiçoados. Esta resposta deve-se ao fato de que vem sendo realizado um controle ambiental pelo Instituto de Radioproteção e Dosimetria (IRD) que monitora os índices ligados à radioatividade em toda a Baía da Ilha Grande. Explica a CNEN que há um monitoramento também permanente, por parte da agência reguladora.

Na terceira questão, sobre as mudanças percebidas quanto à participação da sociedade civil, a maioria considera que a participação da sociedade civil aumentou bastante. No entanto, nota-se que a Empresa sinaliza que há manipulação política envolvida nessa participação, enquanto que a comunidade científica acredita que esse aumento de participação seja o resultado do exercício da cidadania. Já a ONG SAPE entende que apesar do aumento da participação da sociedade, falta-lhe poder de veto. Causa surpresa à pequena importância dada à participação da sociedade civil pelo órgão licenciador e fiscalizador na esfera federal, o IBAMA que entende que a participação da sociedade civil deve se restringir apenas às audiências públicas.

Na quarta questão, sobre que razão está relacionado do aumento do rigor das exigências para o Licenciamento Ambiental - se a uma maior pressão da sociedade civil ou se por maior demanda por empreendimentos energéticos, percebe-se que os entrevistados estão divididos em suas opiniões quanto ao fator determinante para o aumento do rigor na questão do Licenciamento Ambiental, sendo que uma resposta apenas destoa das demais - a que é fornecida pela ONG, que percebe que é graças à pressão da sociedade civil organizada. Já o IBAMA não reconhece uma vinculação entre as duas situações quando verbalizou: "Nem uma coisa, nem outra”. Segundo este órgão, o Licenciamento Ambiental sempre primou pela excelência; há termos de exigências e boas práticas mundialmente conhecidas.

Com a quinta pergunta, investigou-se sobre o que deveria mudar no procedimento administrativo para concessão de Licenciamento Ambiental no Brasil. A maioria dos entrevistados afirma ter propostas para mudar o processo de Licenciamento Ambiental e os Estudos de Impacto Ambiental, mas as propostas não são compartilhadas. As respostas indicam que existem várias áreas de interferência na situação do Licenciamento, exceto o exposto pelo IBAMA que afirma que nada deve ser mudado, o que pode estar sinalizando o isolamento do órgão e falta de articulação deste com os outros sujeitos, principalmente pela 
existência de dois órgãos de licenciamento, porém há poucas propostas para resolvê-los. A ONG enfatiza que há muitos conflitos entre os sujeitos.

Quadro 2 - Interpretação dos Depoimentos dos Entrevistados

\begin{tabular}{|c|c|c|c|c|c|c|c|}
\hline $\begin{array}{l}\begin{array}{l}\text { Empresas } \\
\text { / Órgãos }\end{array} \\
\text { Questões } \\
\text { comuns }\end{array}$ & $\begin{array}{l}\text { ELETRO } \\
\text { NUCLEAR }\end{array}$ & IBAMA & FEEMA & CNEN & $\begin{array}{l}\text { PODER } \\
\text { PÚBLICO } \\
\text { LOCAL }\end{array}$ & $\begin{array}{l}\text { COMUNI- } \\
\text { DADE } \\
\text { CIENTÍ- } \\
\text { FICA }\end{array}$ & ONG SAPE \\
\hline $\begin{array}{l}\text { 1. O que } \\
\text { mudou nos } \\
\text { EIA/RIMA's e } \\
\text { Licencia-mento } \\
\text { Ambiental nas } \\
\text { últimas } \\
\text { décadas? }\end{array}$ & $\begin{array}{c}\text { Tenta } \\
\text { adequar-se. } \\
\text { Na época não } \\
\text { havia } \\
\text { exigência de } \\
\text { EIA/RIMA. }\end{array}$ & $\begin{array}{c}\text { Maior } \\
\text { transparên- } \\
\text { cia e } \\
\text { participação } \\
\text { da } \\
\text { população. }\end{array}$ & $\begin{array}{c}\text { Têm sido } \\
\text { cada vez } \\
\text { mais } \\
\text { aperfeiçoad } \\
\text { os, }\end{array}$ & $\begin{array}{l}\text { Estão cada } \\
\text { vez mais } \\
\text { detalhados e } \\
\text { exigentes. }\end{array}$ & $\begin{array}{l}\text { A Prefeitura } \\
\text { não tem } \\
\text { meios } \\
\text { acompa-nhar } \\
\text { o cumpri- } \\
\text { mento dos } \\
\text { EIA } \\
\text { /RIMA's. }\end{array}$ & $\begin{array}{l}\text { Acompa-nha } \\
\text { as forças de } \\
\text { pressão da } \\
\text { sociedade. } \\
\text { Quanto ao } \\
\text { passado há } \\
\text { poucas } \\
\text { opções } \\
\text { disponí-veis. }\end{array}$ & $\begin{array}{c}\text { Mudou muito } \\
\text { pouco. A } \\
\text { sociedade } \\
\text { não tem } \\
\text { acesso aos } \\
\text { dados } \\
\text { ambientais } \\
\text { preciosos. }\end{array}$ \\
\hline $\begin{array}{l}\text { 2. O que } \\
\text { mudou quanto } \\
\text { aos relatórios } \\
\text { de Controle } \\
\text { Ambiental? }\end{array}$ & $\begin{array}{l}\text { Têm sido } \\
\text { constante- } \\
\text { mente } \\
\text { aperfeiço- } \\
\text { ados. }\end{array}$ & $\begin{array}{c}\text { São } \\
\text { elaborados } \\
\text { de acordo } \\
\text { com o } \\
\text { definido nas } \\
\text { licenças. } \\
\end{array}$ & $\begin{array}{l}\text { Não tem } \\
\text { meios para } \\
\text { analisá-los. }\end{array}$ & $\begin{array}{l}\text { Têm sido } \\
\text { aperfeiço- } \\
\text { ados. }\end{array}$ & $\begin{array}{l}\text { A Prefeitura } \\
\text { não tem } \\
\text { meios para } \\
\text { acompanhar } \\
\text { os Relatórios. }\end{array}$ & $\begin{array}{c}\text { São } \\
\text { adequados e } \\
\text { têm evoluído } \\
\text { bastante. }\end{array}$ & $\begin{array}{l}\text { São dados } \\
\text { muito } \\
\text { técnicos. }\end{array}$ \\
\hline $\begin{array}{l}\text { 3. Quanto à } \\
\text { participação da } \\
\text { sociedade } \\
\text { civil? }\end{array}$ & $\begin{array}{c}\text { Aumentou } \\
\text { bastante, mas } \\
\text { percebe-se } \\
\text { manipula-ção } \\
\text { política. }\end{array}$ & $\begin{array}{l}\text { Durante as } \\
\text { audiências } \\
\text { públicas. }\end{array}$ & $\begin{array}{c}\text { Ela tem } \\
\text { sido mais } \\
\text { participa- } \\
\text { tiva. }\end{array}$ & $\begin{array}{c}\text { Tem sido } \\
\text { cada vez } \\
\text { maior. }\end{array}$ & $\begin{array}{l}\text { A Prefeitura } \\
\text { é impactada } \\
\text { pelo } \\
\text { empreendime } \\
\text { nto. }\end{array}$ & $\begin{array}{c}\text { É o exercício } \\
\text { da } \\
\text { democracia. }\end{array}$ & $\begin{array}{l}\text { A sociedade } \\
\text { civil tem } \\
\text { participado } \\
\text { mas falta o } \\
\text { poder de } \\
\text { veto. }\end{array}$ \\
\hline $\begin{array}{l}\text { 4. O aumento } \\
\text { do rigor para o } \\
\text { Licencia-mento } \\
\text { Ambiental está } \\
\text { vinculado a } \\
\text { que? }\end{array}$ & $\begin{array}{l}\text { Ao aumento } \\
\text { de demanda } \\
\text { por energia. }\end{array}$ & $\begin{array}{l}\text { Nem uma } \\
\text { coisa e nem } \\
\text { outra. }\end{array}$ & $\begin{array}{c}\text { Não } \\
\text { avaliado. }\end{array}$ & $\begin{array}{l}\text { À demanda } \\
\text { por energia. }\end{array}$ & Não percebe. & $\begin{array}{c}\text { Cremos que à } \\
\text { demanda por } \\
\text { energia. }\end{array}$ & $\begin{array}{l}\text { À pressão da } \\
\text { sociedade } \\
\text { civil } \\
\text { organizada. }\end{array}$ \\
\hline $\begin{array}{l}\text { 5. O que } \\
\text { deveria mudar } \\
\text { no Licencia- } \\
\text { mento } \\
\text { Ambiental? }\end{array}$ & $\begin{array}{c}\text { Evitar } \\
\text { duplicidade } \\
\text { de } \\
\text { exigências. }\end{array}$ & Nada. & $\begin{array}{c}\text { Não } \\
\text { avaliado. }\end{array}$ & $\begin{array}{c}\text { Maior } \\
\text { interação e } \\
\text { articulação } \\
\text { entre } \\
\text { IBAMA e } \\
\text { CNEN. }\end{array}$ & $\begin{array}{c}\text { Participação } \\
\text { mais efetiva } \\
\text { do Poder } \\
\text { Público local. }\end{array}$ & $\begin{array}{l}\text { Uma melhor } \\
\text { estrutura-ção } \\
\text { do IBAMA e } \\
\text { da CNEN. }\end{array}$ & $\begin{array}{c}\text { Participa-ção } \\
\text { mais ativa } \\
\text { das ONG's, } \\
\text { sindicatos e } \\
\text { outras } \\
\text { institui-ções } \\
\text { locais. } \\
\end{array}$ \\
\hline $\begin{array}{l}\text { 6. Existem } \\
\text { conflitos entre } \\
\text { órgãos no } \\
\text { licencia-mento } \\
\text { e fiscalização? }\end{array}$ & $\begin{array}{l}\text { Sim, existem } \\
\text { várias áreas } \\
\text { de interferên- } \\
\text { cia. }\end{array}$ & $\begin{array}{c}\text { Sim, existem } \\
\text { várias áreas } \\
\text { de interferên- } \\
\text { cia. }\end{array}$ & $\begin{array}{l}\text { Aparente- } \\
\text { mente } \\
\text { existe um } \\
\text { duplo } \\
\text { Licencia- } \\
\text { mento. } \\
\end{array}$ & $\begin{array}{l}\quad \text { Existe } \\
\text { cooperação } \\
\text { entre órgãos } \\
\text { e problemas } \\
\text { funcionais. }\end{array}$ & Não percebe. & $\begin{array}{c}\text { Sim, existem } \\
\text { várias áreas } \\
\text { de interferên- } \\
\text { cia. }\end{array}$ & $\begin{array}{l}\text { Muitos, a } \\
\text { impressão é } \\
\text { de que não } \\
\text { há entrosa- } \\
\text { mento. }\end{array}$ \\
\hline $\begin{array}{l}\text { 7. O que } \\
\text { mudou quanto } \\
\text { ao acompanha- } \\
\text { mento dos } \\
\text { EIA/RIMA? }\end{array}$ & $\begin{array}{c}\text { A evolução } \\
\text { tem sido } \\
\text { constante. }\end{array}$ & $\begin{array}{l}\text { A legislação } \\
\text { brasileira tem } \\
\text { sido } \\
\text { aperfeiço- } \\
\text { ada. }\end{array}$ & $\begin{array}{l}\text { Evolução } \\
\text { tem sido } \\
\text { constante. }\end{array}$ & $\begin{array}{l}\text { Há interface } \\
\text { entre agência } \\
\text { reguladora e } \\
\text { órgão } \\
\text { ambiental. }\end{array}$ & $\begin{array}{l}\text { A Prefeitura } \\
\text { acompanha } \\
\text { os impactos } \\
\text { ambientais. }\end{array}$ & $\begin{array}{c}\text { Tem } \\
\text { evoluído } \\
\text { bastante. }\end{array}$ & $\begin{array}{c}\text { Houve pouca } \\
\text { mudança, } \\
\text { não são } \\
\text { cumpridas as } \\
\text { leis. }\end{array}$ \\
\hline $\begin{array}{l}\text { 8. A questão } \\
\text { ambiental e } \\
\text { empreendi- } \\
\text { mentos futuros }\end{array}$ & $\begin{array}{l}\text { Já existe } \\
\text { planeja- } \\
\text { mento até } \\
2030 .\end{array}$ & $\begin{array}{c}\text { Já existe } \\
\text { planeja- } \\
\text { mento até } \\
2030 .\end{array}$ & $\begin{array}{l}\text { O órgão irá } \\
\text { ter mais } \\
\text { atribui- } \\
\text { ções. }\end{array}$ & $\begin{array}{c}\text { Será } \\
\text { valorizado o } \\
\text { trabalho do } \\
\text { órgão. }\end{array}$ & $\begin{array}{l}\text { Os impactos } \\
\text { ambientais } \\
\text { irão } \\
\text { aumentar. }\end{array}$ & $\begin{array}{c}\text { As } \\
\text { exigências } \\
\text { aumenta-rão. }\end{array}$ & $\begin{array}{c}\text { Aumenta-rão } \\
\text { os danos } \\
\text { ambientais. }\end{array}$ \\
\hline
\end{tabular}


Fonte: Elaboração própria com base em entrevistas com os sujeitos da pesquisa de abril a dezembro de 2008.

Na sexta questão que indaga sobre a existência de zonas de conflito na atuação dos órgãos, todos afirmam haver conflitos Na sétima questão, sobre o que mudou quanto ao acompanhamento das recomendações dos Estudos de Impactos Ambientais, os sujeitos, em sua maioria, admitem grandes progressos na utilização dos instrumentos de Política Ambiental, os EIA/RIMA's. A ONG SAPE, no entanto, adverte que houve pouca mudança e que os estudos e seus resultados são apenas formais e a legislação não é efetivamente cumprida.

A oitava e última questão trata de como os sujeitos vêem a questão ambiental relacionada aos empreendimentos futuros. Revela-se a necessidade de planejamento de longo prazo. Entretanto, o poder público local e a ONG apresentam um cenário preocupante sinalizando que haverá o aumento de impacto ambiental e danos. Já a comunidade científica acena para o fato de que as exigências sobre os Estudos de Impacto Ambiental e o processo do Licenciamento Ambiental aumentarão. Os representantes da Secretaria Executiva do Ministério do Meio Ambiente e do Ministério Público apresentaram justificativa de tempo para conceder entrevista para a presente pesquisa. A Secretaria Executiva do Ministério do Meio Ambiente havia sido escolhida porque o Ministério do Meio Ambiente é diretamente ligado à Presidência da República e a ele cabe a definição de estratégias para a gestão ambiental pública (MMA, 2009). Por sua vez, o Ministério Público havia sido escolhido porque é o defensor dos direitos da sociedade civil, órgão do Poder Judiciário, com a máxima autoridade sobre quaisquer questões que se levantem sobre meio ambiente (MPF, 2009).

\section{CONCLUSÕES}

O objetivo deste trabalho é analisar, sob a ótica da política pública, os instrumentos de Política Ambiental, que se intitulam Estudos de Impacto Ambiental e Licenciamento Ambiental, abordando criticamente a articulação político-institucional na utilização dos mesmos. Verificou-se quais são as dificuldades político-institucionais e não somente técnicas hoje postas à utilização desses instrumentos assim como a situação interinstitucional que influencia as condições para a incorporação dos mesmos na gestão empresarial no Brasil, a partir da experiência de uma empresa brasileira de grande porte, a Eletrobrás Termonuclear S. A. (Eletronuclear).

A idéia de que a área dos estudos organizacionais pode beneficiar-se de uma visão mais abrangente dos processos de institucionalização, que inclui a dimensão do poder, conforme apontado por Peci (2006), ao invés de considerarmos as instituições como variáveis dadas e imutáveis, encontra um campo fértil no presente estudo, pois a pesquisa permite evidenciar contínuas mudanças por que passam as instituições e revelar relações de poder no âmbito das articulações e desarticulações interinstitucionais verificadas no estudo, o que foi possibilitado pela abordagem crítica dessas questões.

Confirma-se na pesquisa a contribuição do neoinstitucionalismo na argumentação de Scott (1983) e de Crubellate (2007). Percebe-se que a correlação entre estruturas e ações organizacionais é circular uma vez que, do mesmo modo que as estruturas organizacionais sofrem influência de ações institucionais, estas últimas podem sofrer pressão das organizações para adotarem mudanças.

Evidenciou-se uma evolução no Brasil no que diz respeito à utilização dos EIA's e do Licenciamento Ambiental, com o aprofundamento do tratamento das questões ambientais. Entretanto os sujeitos diretamente envolvidos na formulação, execução e controle dos instrumentos não apresentam preocupações e propostas de soluções compartilhadas, com 
vistas ao uso dos instrumentos, seu aprimoramento e a possibilidade de serem internalizados nos procedimentos da gestão empresarial.

Os resultados da pesquisa revelam que há uma maior participação da sociedade civil e uma maior disposição da empresa para absorver o aperfeiçoamento dos procedimentos de Licenciamento Ambiental. No entanto, ainda há um longo caminho a percorrer para um envolvimento mais decisivo e consequente. Uma situação reveladora da limitação de poder da sociedade civil manifesta-se nas audiências públicas, por esta não possuir poder de veto, conforme depoimentos dos entrevistados. Entretanto, ocorrem mudanças por meio de ações da sociedade civil, representada pelo Ministério Público. Por exemplo, o Ministério encaminhou um acordo entre o órgão regulador e licenciador, a CNEN e a Eletronuclear que resultou no Termo de Ajustamento de Conduta (TAC) para a criação de um programa de monitoramento ambiental com Georreferenciamento no entorno da Baía da Ilha Grande financiado pela Eletronuclear e que deverá gerar um banco de dados significativo, com informações ambientais e sócio-econômicas sobre a região em torno da empresa. Esse passo é decorrência de exigência em audiência pública concretizado pelo TAC.

$\mathrm{Na}$ pesquisa empírica evidenciaram-se descontentamentos dos sujeitos sobre a duplicidade e interferência na atuação de órgãos ambientais de regulação e de licenciamento, gerando superposição de responsabilidades. Esses descontentamentos podem, no entanto, estar camuflando uma situação mais conflituosa entre os sujeitos, pela divergência de interesses nas decisões e nos encaminhamentos das soluções, conforme os estudos de Nunes (1997; 2001) sobre o insulamento burocrático das agências reguladoras, mesmo que aparentemente, não revelada com a força da ênfase dada por Nunes, quando o autor se refere ao "selvagem campo de lutas de interesses", entre os sujeitos. O fato é que nesse contexto, percebe-se o isolamento do IBAMA e uma desarticulação deste com os outros órgãos. A escolha da Eletronuclear, mesmo apresentando dinâmicas específicas setoriais relativas à energia nuclear, não desautoriza a pesquisa a sugerir que a situação revelada no estudo, de desarticulação interinstitucional, possa estar presente também em outras empresas brasileiras cujas atividades econômico-produtivas estejam sujeitas a obrigatoriedade de Estudos de Impacto Ambiental e de Licenciamento Ambiental, para funcionarem.

\section{REFERÊNCIAS}

Barbieri, J. C. (2007). Gestão Ambiental Empresarial. 2a ed. Saraiva: São Paulo.

Bolea, M. T. E. (1984). Evaluacion del Impacto Ambiental. Mapfre: Madrid.

Brasil/Conama - Conselho Nacional De Meio Ambiente. Resolução CONAMA n ${ }^{0} 237$ de 19 de dezembro de 1997, Brasília. Disponível em www.mma.gov.br. Acesso em 12 de agosto 2008.

Crubellate, J. M. (2007). Três Contribuições Conceituais Neofuncionalistas à Teoria Institucional em Organizações. In: Revista de Administração Contemporânea. $1^{\mathrm{a}}$ ed. Especial, ANPAD: Curitiba, p. 199-222.

Eletronuclear - Eletrobrás Termonuclear S.A., http:www.eletronuclear.gov.br/meio_ ambiente, acessado em 15 de fevereiro de 2008.

Gianetti, B. F.; Almeida, C. M. V. B. (2006). Ecologia Industrial: Conceitos, Ferramentas e Aplicações. Edgard Blucher: Rio de Janeiro. 
Godoy, A. S. (1995). Introdução à pesquisa qualitativa e suas possibilidades. Revista de Administração de Empresas. v. 35, nº 3, FGV: São Paulo.

Habermas, J. (1984). The Theory of Communicative Action. v.1 Reasons and the Racionalization of Society. Beacon Press: Boston.

Ibama - Instituto Brasileiro do Meio Ambiente e dos Recursos Naturais Renováveis. http://www.ibama.gov.br, acessado em 21 de fevereiro de 2008.

Hodgson, G. (1988). Economics and Institutions. Polity Press: cambridgeUK.

Lustosa, M. C.; Cánepa, E. M.; Young, C. E. (2003). Política Ambiental. In: May, Peter H.; Lustosa, M. Cecília; Vinha, Valéria (Orgs.). Economia do Meio Ambiente. Campus: Rio de Janeiro, p. 135-153.

Lustosa, M. C. (2003). Industrialização, Meio Ambiente, Inovação e Competitividade. In: May, Peter H.; Lustosa, M. Cecília; Vinha, Valéria (Orgs.). Economia do Meio Ambiente. Campus: Rio de Janeiro, p. 136-172.

Magrini, A. (1989). Avaliação de Impacto Ambiental em Aspectos Técnicos e Econômicos do Meio Ambiente. In: CENDEC, Brasília, 1989.

Ministério do Meio Ambiente, Extraído do site www.mma.gov.br, acessado em 28 de janeiro de 2009.

Ministério Público Federal, Extraído do site http://www2.pgr.mpf.gov.br/, acessado em 28 de janeiro de 2009.

Mishler, E. G. (1986). Research Interviewing: Context and Narrative. Harvard University Press: Cambridge, Mass.

Nunes, E. A gramática política do Brasil - clientelismo e insulamento burocrático. $\quad 3^{\mathrm{a}}$ ed. Jorge Zahar: Rio de Janeiro; ENAP: Brasília, 1997.

Nunes, E. (2001). O quarto poder: gênese, contexto e controle das agências regulatórias. In: Anais do Seminário Internacional sobre Agências Reguladoras de Serviços Públicos. Brasília.

Oliveira, L. A.; Borges, C. A.; Melhado, S. B. Sistemas de Gestão Integrados: Análise em uma Empresa-Construtora. In: Departamento de Construção Civil - PCC, Escola Politécnica da USP, http://www.poli.usp.br, acessado em 20 de dezembro de 2007, p. 1-10.

Oliveira, R. (2003). Ascensão e Declínio de um Padrão Institucional. Estudo de caso da Companhia Hidroelétrica do São Francisco (CHESF). In: Vieira e Carvalho (Orgs.). Organizações, Instituições e Poder no Brasil. FGV: Rio de Janeiro, p. 227-269.

Peci, A. (2008). A nova teoria institucional em estudos organizacionais: uma abordagem crítica. FGV/RJ: Cadernos EBAPE., v. 4, nº 1, Mar. 2006. 
Pnmc - Plano Nacional Sobre Mudança Do Clima. Governo Federal. Comitê Interministerial sobre mudança do Clima. Decreto $n^{0} 6.263$ de 21 de novembro de 2007. Versão para consulta pública.

Porto, C.; Belfort, A. (2006). Perspectiva Institucional e Organizacional. In: Pires, A; Fernandez, E.; Bueno, J. (Orgs.). Política Energética para o Brasil. Nova Fronteira: Rio de Janeiro, p. 92-118.

Roesch, S. M. (2007). Projetos de Estágio e Pesquisa em Administração. $3^{\mathrm{a}}$ ed. Atlas: São Paulo.

Scott, W. R. (1983). The organizations of environments: networks, cultural and historical elements. In: Meyer, J. W. \& Scott, W. R. (Orgs.). Organizational environments: ritual and rationality. Sage: London, p. 155-175.

Selznick, P. (1996). Institutionalism “old” and “new”. Administrative Science Quarterly, v.41, n 2, p.270-277.

Souza, A. N.; Jacobi, P. R. (2007). A Indústria do Alumínio no Brasil e suas Hidrelétricas sob a Perspectiva da Modernização Ecológica. In: Anais do IX ENGEMA - Encontro Nacional sobre Gestão Empresarial e Meio Ambiente. Curitiba, p. 1-17.

Teixeira, M. G. C.; Bessa, E. S. Rima (1990). Instrumento Técnico ou Instrumento Político de Planejamento Ambiental? Contribuições para um estudo crítico da sua utilização. In: Anais do $V$ Congresso Brasileiro de Energia. COPPE/UFRJ e Clube de Engenharia: Rio de Janeiro, vol. 3/3, p. 1243-1251.

Teixeira, M. G. C.; Souza, R. C. De; Magrini, A.; Rosa, L. P. (1994). Análise dos Relatórios de Impactos Ambientais de Grandes Hidrelétricas no Brasil. In: Muller-Plantenberg, Clarita; Ab’Saber, Aziz (Orgs.). Previsão de Impactos. EDUSP: São Paulo, p. 163-186.

Westman, W. E. (1985). Ecology, Impact Assessment and Environmental Planning. John Wiley and Sons: New York. 